\title{
Investigating travertine laminae formed in Honey Creek within the Arbuckle Mountains of Oklahoma
}

\author{
ELIZABETH M. GRIFFITH ${ }^{1}$, MAJIE FAN ${ }^{2}$, AND ARADHNA \\ TRIPATI $^{3}$
}

${ }^{1}$ The Ohio State University, griffith.906@osu.edu

${ }^{2}$ The University of Texas at Arlington,mfan@uta.edu

${ }^{3}$ University of California, Los Angeles,

ripple@epss.ucla.edu

Laminated travertine can be seen in modern and ancient settings and have been suggested to be deposited due to seasonal changes in biological activity which might impart changes in stable isotopic and elemental signatures of the laminae. Over four seasons (May 2016 to May 2017), travertine samples were collected on experimental substrates (glass slides), and ambient temperature was recorded hourly using a Onset HOBO temperature logger in Honey Creek within the Arbuckle Mountains of Oklahoma. Water samples and other in situ data were also collected and analyzed at several locations in the creek and in a spring fed tributary to determine seasonal aqueous chemistry and identify factors influencing travertine precipitation. We observed that travertine precipitated much faster during the warm season than cold season. The clumped isotope compositions $\left(\Delta_{47}\right)$ vary from $0.740 \%$ in winter to $0.680 \%$ o in summer and fall, reflecting a change of temperature from $\sim 7^{\circ} \mathrm{C}$ to $\sim 23^{\circ} \mathrm{C}$, consisitent with the water temperature data. The calculated water $\delta^{18} \mathrm{O}$ values changed from $-6.1 \%$ in winter to $-4.6 \%$ in summer and fall. Stable calcium isotopes will be measured on the same samples to identify any seasonal variations and the controling factors of calcium isotopic fractionation. This study shows that travertine deposition and its clumped isotope temperature bias to warm seasons. 